\title{
Pseudosclerosing cholangitis in extrahepatic portal venous obstruction
}

\author{
J B Dilawari, Y K Chawla
}

\begin{abstract}
Biliary changes secondary to portal hypertension have rarely been described in published reports. Twenty consecutive patients with extrahepatic portal venous obstruction, all of whom showed a variable degree of abnormalities in the biliary tract suggestive of sclerosing cholangitis, are described. These biliary abnormalities were: focal narrowing, dilatations, and cholangitic changes affecting the main bile ducts and hepatic ducts. The left hepatic duct and its branches were affected in all patients. Only one patient had clinical or biochemical evidence of cholestasis. The mechanism of these abnormalities in the biliary tract of these patients is perhaps the development of portal collaterals.
\end{abstract}

There are only a few case reports of biliary changes in patients with portal hypertension, ${ }^{1-4}$ and most are of patients with extrahepatic portal venous obstruction. We studied the frequency of biliary changes in patients with extrahepatic portal venous obstruction by endoscopic retrograde cholangiopancreatography (ERCP). To the best of our knowledge this is the first report describing biliary abnormalities in such patients.

Department of

Hepatology,

Postgraduate Institute of

Medical Education and

Research, Chandigarh,

India

J B Dilawari

Y K Chawla

Correspondence to:

Dr J B Dilawari, Department of Hepatology, Postgraduate Institute of Medical Education and Research, Chandigarh 160012 , India.

Accepted for publication 15 April 1991

\section{Methods}

ERCP

ERCP was performed by the standard technique using a side viewing duodenoscope (Olympus JF 10) to delineate the intra- and extrahepatic biliary system and pancreatic duct. Patients received premedication with intravenous diazepam $(10 \mathrm{mg})$ and hyoscine hydrochloride $(40 \mathrm{mg})$ before ERCP. All the patients gave informed consent. They were told about the

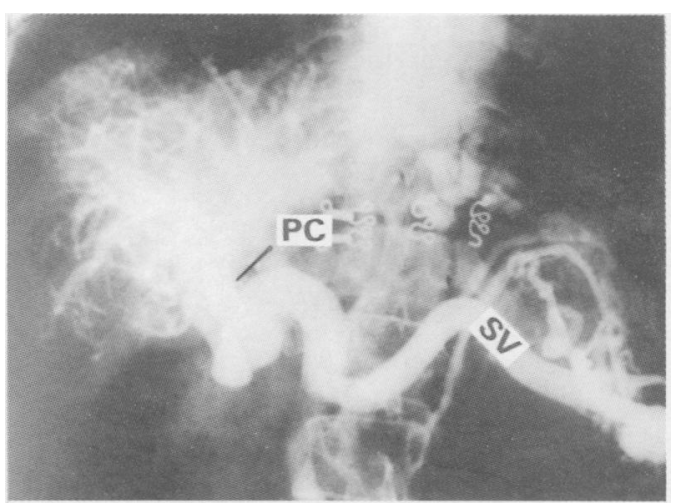

procedure and what we were looking for and advised that the ERCP findings would probably have little bearing on their management.

\section{SPLENOPORTOVENOGRAPHY}

Percutaneous splenoportovenography was done under fluoroscopic control using $40 \mathrm{ml}$ of Conray 420 (sodium iothalamate BP) by the standard technique $^{5}$ (Fig 1). Six films at the rate of $1 /$ second were taken. Spontaneous splenorenal shunt was defined when contrast, injected into the splenic pulp, was seen entering the inferior vena cava through collaterals between the splenic and renal veins.

\section{SPLENIC PULP PRESSURE}

Splenic pulp pressure was measured using an electronic pressure recorder (Siemens mingograph) at the time of splenoportovenography.

\section{OESOPHAGOGASTRODUODENSCOPY}

Upper gastrointestinal endoscopy was undertaken to look for any mucosal lesion in the oesophagus, stomach, or duodenum. Oesophageal varices, if present, were graded according to the criteria of Paquet ${ }^{6}$ (grade I-IV).

PATIENTS

Two groups of patients were included in the study.

\section{Control group}

The control group comprised 15 age and sex matched patients with a history of abdominal pain suggestive of pancreatic disease but with a normal upper gastrointestinal endoscopy and ERCP. Patients in both the groups were clinically assessed for any biliary symptoms. Liver function tests were done in all.

Extrahepatic portal venous obstruction

Twenty consecutive patients with an established diagnosis of extrahepatic portal venous obstruction by splenoportovenography and splenic pulp pressure were included in this group. All had a previous history of massive upper gastrointestinal bleed, large varices (grades III-IV) on endoscopy, and a moderately enlarged spleen. All patients, except one, underwent repeated sessions of endoscopic sclerotherapy. Obliteration of varices was achieved in 17 patients at the time of ERCP. Successful ERCP was performed in all 20. There were 16 men and four women, and the average age was 22 years (Table I).
Figure 1:

Splenoportovenogram showing portal cavernoma $(P C)$ instead of a well defined portal vein in hypertension $S V=$ splenic vein.

.


TABLE I Parameters studied in 20 patients with extrahepatic portal venous obstruction

\begin{tabular}{|c|c|c|c|c|c|c|c|c|c|c|c|}
\hline & $\begin{array}{l}\text { Age } \\
\text { sex }\end{array}$ & $\begin{array}{l}D O I \\
\text { (yrs) }\end{array}$ & $\begin{array}{l}S P L \\
(\mathrm{~cm})\end{array}$ & $S O B$ & $\begin{array}{l}S P P \\
(m m H g)\end{array}$ & $\begin{array}{l}E S T \\
(n o)\end{array}$ & $\begin{array}{l}\text { EST } \\
\text { Res }\end{array}$ & $\begin{array}{l}\text { Interval } \\
\text { OBL-ERCP } \\
\text { (mths) }\end{array}$ & $\begin{array}{l}M B D \\
\text { max diam } \\
(\text { mm }) / \text { findings }\end{array}$ & $\begin{array}{l}\text { LHD } \\
\text { max diam } \\
(\text { mm }) / \text { findings }\end{array}$ & $\begin{array}{l}\text { RHD } \\
\text { max diam } \\
(\operatorname{mm}) / \text { findings }\end{array}$ \\
\hline $\begin{array}{l}\text { Mean } \\
\text { (S/D) }\end{array}$ & $\begin{array}{l}38 \mathrm{M} \\
24 \mathrm{M} \\
21 \mathrm{~F} \\
21 \mathrm{~F} \\
18 \mathrm{M} \\
18 \mathrm{M} \\
27 \mathrm{~F} \\
20 \mathrm{M} \\
16 \mathrm{M} \\
19 \mathrm{M} \\
13 \mathrm{~F} \\
15 \mathrm{M} \\
23 \mathrm{M} \\
18 \mathrm{M} \\
21 \mathrm{M} \\
25 \mathrm{M} \\
34 \mathrm{M} \\
24 \mathrm{M} \\
29 \mathrm{M} \\
17 \mathrm{M} \\
22 \\
(6)\end{array}$ & $\begin{array}{r}7 \\
4 \\
11 \\
10 \\
2 \\
6 \\
7 \\
4 \\
1 \\
3 \\
4 \\
1 \\
1 \\
2 \\
14 \\
8 \\
5 \\
1 \\
10 \\
11 \\
5.6 \\
(3.8)\end{array}$ & $\begin{array}{c}5 \\
3 \\
8 \\
8 \\
5 \\
16 \\
12 \\
10 \\
3 \\
7 \\
6 \\
5 \\
4 \\
12 \\
3 \\
6 \\
3 \\
\text { SPLX } \\
\text { SPLX } \\
13 \\
7.1 \\
(3 \cdot 8)\end{array}$ & $\begin{array}{l}\text { PVT (D) } \\
\text { PVT (D) } \\
\text { PVT (D) } \\
\text { PVT } \\
\text { PVT } \\
\text { PVT } \\
\text { PVT } \\
\text { PVT } \\
\text { PVT } \\
\text { PVT } \\
\text { PVT } \\
\text { CB } \\
\text { CB } \\
\text { CB } \\
\text { CB (SRS) } \\
\text { CB (SRS) } \\
\text { CB (SRS) } \\
\text { SS (T) } \\
\text { SS (T) } \\
\text { SS (T) } \\
- \\
-\end{array}$ & $\begin{array}{l}44 \cdot 5 \\
28 \cdot 5 \\
36 \cdot 1 \\
31 \cdot 6 \\
30 \\
36 \cdot 1 \\
27 \\
44 \cdot 6 \\
30 \\
30 \\
33 \\
27 \\
37 \\
35 \\
35 \\
34 \cdot 6 \\
20 \\
- \\
- \\
38 \\
33 \cdot 2 \\
(5 \cdot 9)\end{array}$ & $\begin{array}{l}3 \\
5 \\
6 \\
0 \\
6 \\
3 \\
5 \\
2 \\
3 \\
9 \\
5 \\
4 \\
6 \\
5 \\
3 \\
6 \\
5 \\
3 \\
6 \\
6 \\
5 \cdot 0 \\
(1 \cdot 5)\end{array}$ & $\begin{array}{l}\text { OBL } \\
\text { OBL } \\
\text { OBL } \\
\text { IV } \\
\text { OBL } \\
\text { III } \\
\text { OBL } \\
\text { III } \\
\text { OBL } \\
\text { OBL } \\
\text { OBL } \\
\text { OBL } \\
\text { OBL } \\
\text { OBL } \\
\text { OBL } \\
\text { OBL } \\
\text { OBL } \\
\text { OBL } \\
\text { OBL } \\
\text { OBL } \\
- \\
-\end{array}$ & $\begin{array}{l}2 \\
42 \\
10 \\
-20 \\
- \\
22 \\
- \\
49 \\
4 \\
10 \\
9 \\
28 \\
34 \\
29 \\
18 \\
17 \\
38 \\
27 \\
20 \\
22 \cdot 3 \\
(12 \cdot 9)\end{array}$ & $\begin{array}{l}6 \text { IND } \\
9 \text { IND, LNR } \\
7 \text { IND } \\
5 \text { IND, LNR } \\
4 \text { IND } \\
8 \text { IND } \\
6 \text { IND } \\
6 \text { IND, LNR } \\
5 \text { IND } \\
5 \text { IND } \\
11 \text { IND } \\
7 \text { IND, LNR } \\
10 \text { IND } \\
8 \text { STONE } \\
8 \text { IND, LNR } \\
7 \text { IND } \\
7 \text { IND } \\
2 \text { IND } \\
7 \text { IND } \\
5 \text { IND } \\
6 \cdot 7 \\
(2 \cdot 1)\end{array}$ & $\begin{array}{l}5 \text { SEV } \\
9 \mathrm{MOD} \\
6 \mathrm{SEV} \\
8 \mathrm{SEV} \\
4 \mathrm{MOD} \\
4 \mathrm{MOD} \\
11 \mathrm{SEV} \\
6 \mathrm{SEV} \\
6 \mathrm{MOD} \\
5 \mathrm{MOD} \\
7 \mathrm{MOD} \\
4 \mathrm{MOD} \\
16 \mathrm{SEV} \\
2 \mathrm{MOD} \\
7 \mathrm{SEV} \\
8 \mathrm{SEV} \\
4 \mathrm{SEV} \\
7 \mathrm{SEV} \\
5 \mathrm{MOD} \\
7 \mathrm{MOD} \\
6 \cdot 5 \\
(3.0)\end{array}$ & $\begin{array}{l}5 \mathrm{MOD} \\
7 \mathrm{MOD} \\
\text { IF } \\
7 \mathrm{SEV} \\
2 \mathrm{NML} \\
3 \mathrm{MOD} \\
4 \mathrm{NML} \\
\text { IF } \\
2 \mathrm{NML} \\
\text { IF } \\
8 \mathrm{SEV} \\
3 \mathrm{NML} \\
9 \mathrm{MOD} \\
4 \mathrm{MOD} \\
4 \mathrm{NML} \\
7 \mathrm{SEV} \\
3 \mathrm{SEV} \\
\text { IF } \\
5 \mathrm{MOD} \\
2 \mathrm{NML} \\
4 \cdot 7 \\
(2 \cdot 3)\end{array}$ \\
\hline
\end{tabular}

$\mathrm{DOI}=$ duration of illness; SPL = spleen; SPLX = splenectomy; SOB = site of block; PVT(D)=portal vein thrombosis (distal); $\mathrm{CB}=$ complete block of splenoportalaxis; $(\mathrm{SRS})=$ splenorenal shunt; $\mathrm{SS}(\mathrm{T})=$ surgical shunt (thrombosed); $\mathrm{SPP}=$ splenic pulp pressure; EST =endoscopic sclerotherapy; $\operatorname{Res}=$ Result; $\mathrm{OBL}=$ obliteration of varices; $M B D=$ main bile duct; IND $=$ indentations;

LNR = localised narrowing; $L H D=$ left hepatic duct; $R H D=$ right hepatic duct; $S E V=$ severe changes; $M O D=$ moderate changes;

$\mathrm{NML}=$ normal; $\mathrm{IF}=$ inadequate filling.

\section{Results}

The papilla and the pancreatic duct were normal in both the groups of patients.

\section{CONTROL GROUP}

None of the patients gave any history of biliary disease and their liver function tests were normal. The main bile duct in this group was almost of uniform diameter in the upper, middle, and lower segments. The mean (SD) maximum diameter of the main bile duct was $4.8(1.3) \mathrm{mm}$, which was significantly greater than the mean diameters of the left and right hepatic ducts (Table II). The left hepatic duct was wider than the right hepatic duct. The walls of the main bile duct, left hepatic duct, and right hepatic duct were smooth and regular. The intrahepatic ducts on both sides were smooth and had a regular branching pattern.

\section{EXTRAHEPATIC PORTAL VENOUS OBSTRUCTION GROUP}

Nineteen of 20 patients did not have any history of biliary disease. Only one patient had biliary colic, with a bilirubin concentration of $1.6 \mathrm{mg}$ and an alkaline phosphatase activity of 219 IU (normal range 70-140 IU). This patient had two small stones in the bile duct. All other patients had normal liver function tests.

\section{Main bile duct}

Eighteen of $20(90 \%)$ patients had abnormalities

TABLE II Mean maximum diameters ( $\mathrm{mm}$ ) of biliary ducts

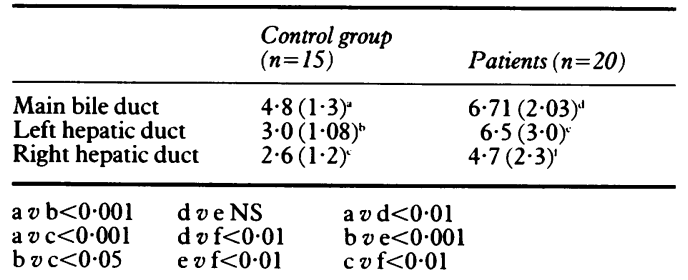

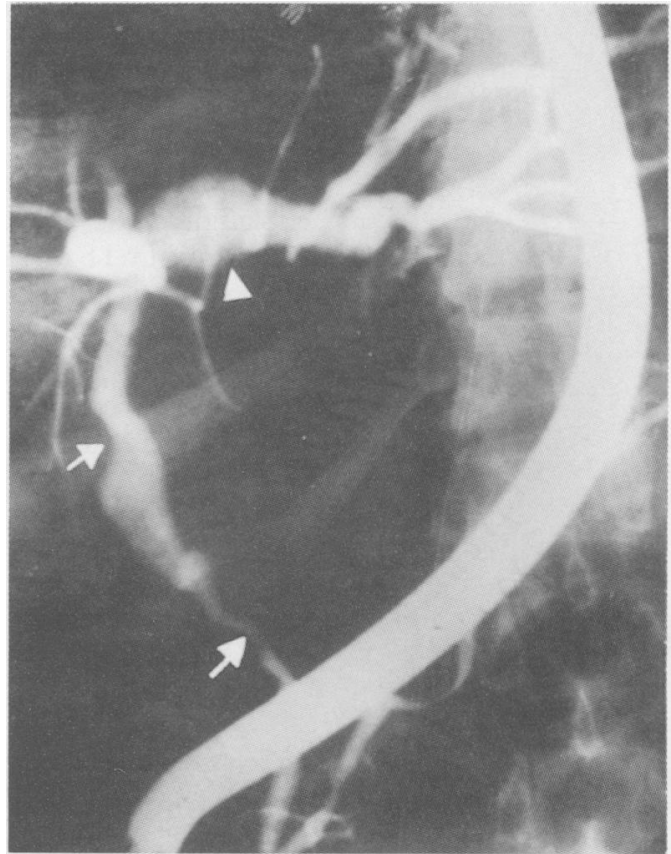

Figure 2: Indentations in the main bile duct (arrowed) due to choledochal varices and dilatation of the left hepatic duct simulating sclerosing cholangitis in a patient with extrahepatic portal venous obstruction.

confined to the mid portion of the main bile duct (Fig 2). All 18 had indentations suggestive of external compression by choledochal varices. Five patients had localised narrow segments in the main bile duct (Fig 3). The mean (SD) maximum diameter of the main bile duct was $6 \cdot 7$ $(2 \cdot 1) \mathrm{mm}$, which was significantly greater than in controls (Table II). In one patient the main bile duct was normal looking but there were two small stones in it, while another patient had abnormalities (narrowing and irregularity) confined to the lower portion.

\section{Left hepatic duct and its branches}

All patients had an abnormal looking left hepatic duct and branches. The abnormalities were as 


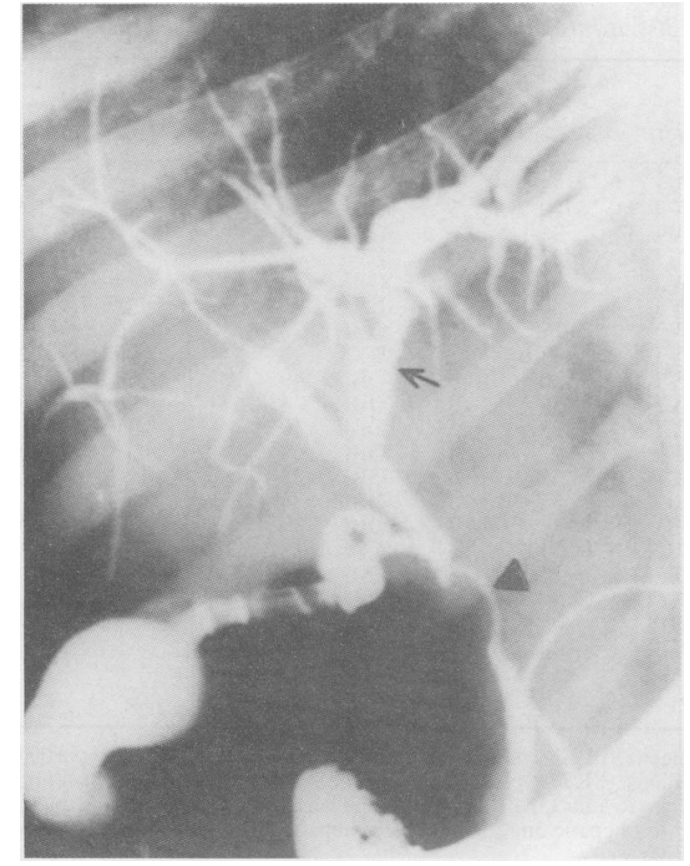

Figure 3: Narrowed mid-segment of the main bile duct (arrowed) with irregular and dilated left hepatic duct in extrahepatic portal venous obstruction.

follows: focal narrowing, dilatations, irregular walls, and clustering of intrahepatic branches. All these changes were suggestive of sclerosing cholangitis. Severe abnormalities (Figs 2-4) were seen in 11 of $20(55 \%)$ while nine $(45 \%)$ patients had moderate changes (Fig 5). The mean (SD) maximum diameter of the left hepatic duct was $6.5(3.0) \mathrm{mm}$, which was significantly more than in controls. Unlike in control subjects, the left hepatic duct in patients with extrahepatic portal venous obstruction was as wide as the main bile duct (Table II).

\section{Right hepatic duct and its branches}

The abnormalities were similar to the ones seen

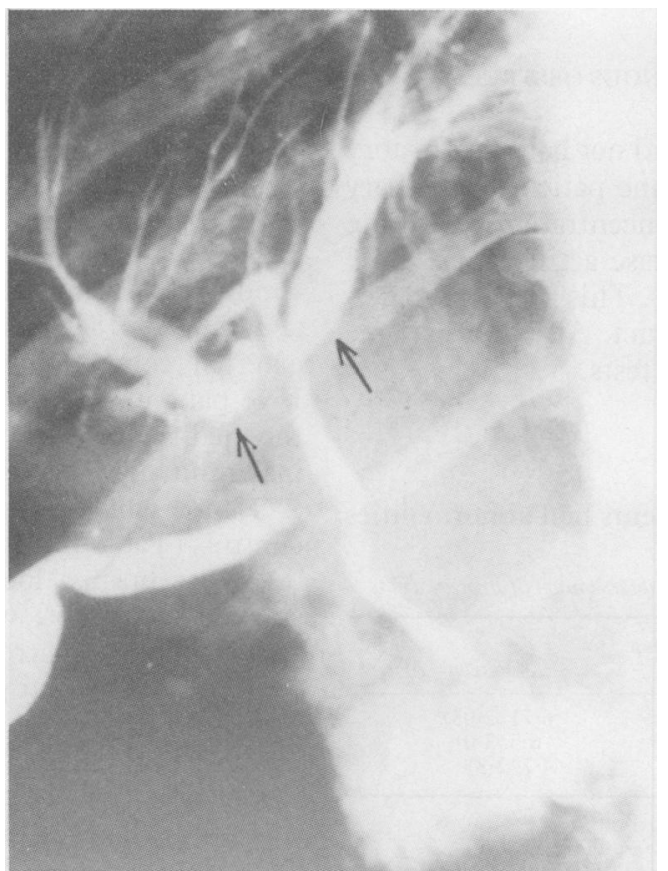

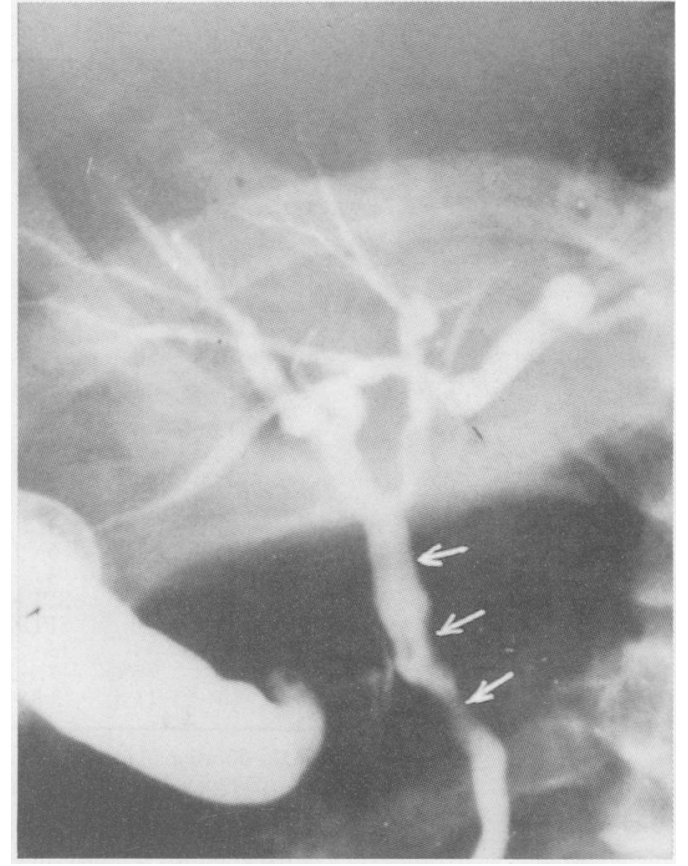

Figure 5: Indentations of the main bile duct (arrowed) with moderate changes in the left and right hepatic ducts in extrahepatic portal venous obstruction.

in the left hepatic duct but with a lesser degree of severity. Moreover, these were not present in all patients. Four of the $20(20 \%)$ did not have adequate filling of the right hepatic duct and hence results could not be analysed. Of the remaining 16 patients, severe changes were seen in three (19\%), moderate changes in six $(37 \cdot 5 \%)$, and seven $(43.5 \%)$ were normal. The mean (SD) maximum diameter was $4 \cdot 7(2 \cdot 3) \mathrm{mm}$, which was significantly greater than in controls. However, it was significantly less compared with the left hepatic duct in these patients (Table II).

\section{Cystic duct and gall bladder}

Because of natural tortuosity of the cystic duct and odd mixing of contrast with the bile of the gall bladder, it was difficult to assess mild to moderate abnormalities. No major or obvious abnormalities were detected. None of the patients had gall stones in the gall bladder.

Other features in patients with extrahepatic portal venous obstruction (Table I)

Other features in these patients were as follows:

(a) Splenomegaly. The spleen was moderately enlarged and was palpable a mean (SD) of $7 \cdot 16$ $(3 \cdot 83) \mathrm{cm}$ below the left costal margin.

(b) Site of block in splenoportovenous axis. Three patients had distal portal vein thrombosis - that is, thrombosis of the portal vein at the junction of the left and right portal veins. Eight patients had complete portal vein thrombosis. Six patients had block at the splenoportal axis, and three of these had a spontaneous splenorenal shunt. Three patients had a thrombosed surgical splenorenal shunt. The extent of the block in the portal venous axis did not correlate with the severity of the biliary abnormalities seen in the main bile duct and left and right hepatic ducts. All patients had massive collateral veins 
(cavernoma) at the porta hepatitis because of portal vein obstruction (Fig 1).

(c) Splenic pulp pressure. This was recorded in 18 patients. All patients had a raised splenic pulp pressure (normal values up to $15 \mathrm{~mm} \mathrm{Hg}$ ), the mean (SD) being $33.2(5.9) \mathrm{mm} \mathrm{Hg}$ (range $20-44.6 \mathrm{~mm} \mathrm{Hg}$ ). The severity of biliary changes did not correlate with splenic pulp presure.

(d) Oesophageal varices. All patients, except one, had undergone sclerotherapy. Oesophageal varices resolved in 17 of the 20 patients and required a mean (SD) of $5.05(1.5)$ sessions of sclerotherapy. Two patients in whom varices did not resolve had received only two and three sessions of sclerotherapy respectively. The mean (SD) interval between resolution of varices and ERCP was 22.29 (12.9) months. The varices were either absent or thrombosed in the 17 patients in whom obliteration had been achieved, while they were large (grades III-IV) in three patients who still had them.

\section{Discussion}

Extrahepatic portal venous obstruction is a frequent cause of portal hypertension in India. In our recent analysis of 521 patients with portal hypertension, three main types were identified: $41 \%$ had cirrhosis, $40 \%$ had extrahepatic portal venous obstruction, and $18 \%$ had non-cirrhotic portal fibrosis. ${ }^{7}$ In over $90 \%$ of our patients with extrahepatic portal venous obstruction, the aetiology was not known.

We have, for the first time, shown biliary changes suggestive of sclerosing cholangitis in $100 \%$ of 20 consecutive patients with portal hypertension caused by extrahepatic portal venous obstruction. These changes were most noticeable in the left hepatic duct and its branches. They were seen in this duct in all patients, whereas only $56 \%$ had changes in the right hepatic duct. The mid portion of the main bile duct was affected in $90 \%$ of the patients. The biliary changes observed in this study did not relate to the degree of portal hypertension, the site of the block in extrahepatic portal venous obstruction, on splenomegaly. Resolution of varices probably had no influence on biliary abnormalities, as three patients without resolution (varices grades III-IV) had biliary changes similar to those in patients whose oesophageal varices had been successfully treated.

Portal hypertension secondary to biliary disorders such as primary cirrhosis and primary or secondary sclerosing cholangitis is well known. Biliary changes secondary to portal hypertension are extremely rare, however, and have been described only in case reports. ${ }^{1+}$ Most of these reports are of patients with extrahepatic portal venous obstruction, because varices as a consequence of portal hypertension are much more common, prominent, and of longer duration in these patients than in those with cirrhosis. ${ }^{8}$ In support of this observation we have recently shown a significantly increased frequency of anorectal varices, large oesophageal varices, and variceal bleeding in patients with extrahepatic portal venous obstruction compared with those with cirrhosis. ${ }^{9}$ The finding of biliary changes possibly caused by choledochal varices in patients with extrahepatic portal venous obstruction further supports this observation.

The biliary abnormalities can be explained by the presence of two types of venous system along the biliary tract. Firstly, the paracholedochal veins seen along the bile duct ${ }^{10}$ joining the gastric and pancreaticoduodenal veins to the portal veins in the liver. Secondly, the epicholedochal veins which form a network around the bile duct. ${ }^{11}$ With obstruction in the main portal vein, as happens in extrahepatic portal venous obstruction, the paracholedochal veins may become prominent and cause indentations on the bile duct. The enlargement of epicholedochal veins may cause irregularity in the walls of the bile duct which may look like cholantgitis.

The type of abnormalities seen in the bile ducts, particularly in the left hepatic duct, are similar to the radiological findings in sclerosing cholangitis. Only one of these patients, however, had any evidence of either cholangitis or biochemical abnormalities of cholestasis. The radiological abnormalites were noticeable in the branches of left hepatic duct and this may be due to the formation of prominent collateral veins where the umbilical vein joins the left branch of the portal vein.

One study has reported somewhat similar changes caused by regenerating nodules and severe fibrosis in the intrahepatic bile ducts of patients with cirrhosis. ${ }^{12}$ In their study, however, the common bile ducts was normal, unlike that in our patients almost all of whom showed indentations. Moreover, intrahepatic bile changes in extrahepatic portal venous obstruction are certainly not caused by regenerating nodules and severe fibrosis, as these are almost always absent in this disorder. Abnormalities in the common duct similar to the ones seen in extrahepatic portal venous obstruction may be caused by lymphoma, biliary tumours, and parasitic infestations. ${ }^{23}$ None of our patients had these conditions.

Choledochal varices in a patient with portal hypertension are very important from a surgical point of view. They prevent satisfactory exploration of the common bile duct, which at the time may even be difficult to recognise, and these varices can be mistaken for the bile duct. ${ }^{3}$ Patients like these who have bile duct stones may be candidates for non-surgical therapy. Rarely, the varices may cause haemobilia after liver biopsy or transhepatic cholangiography. ${ }^{131+}$ Jaundice secondary to the obstruction of the bile duct by enlarged choledochal varices occurs rarely. This phenomenon was first described by Fraser and Brown in 1944, ${ }^{15}$ and quite recently by Choudhary et al, ${ }^{16}$ who showed improvement of jaundice and the cholangiogram after successful shunt surgery in a patient with extrahepatic portal venous obstruction. Of the 213 patients with extrahepatic portal venous obstruction seen in our centre, only two had jaundice in addition to the problems of portal hypertension. Both these patients had multiple stones in both the intra- and extrahepatic bile ducts.

None of our patients, except one who had stones in the common bile duct, had raised bilirubin or alkaline phosphatase values despite narrowing of the bile ducts. We presume that 
this could be a result of the intermittent forceful contractions of gall bladder in response to the ingestion of food which cause an increase in the intraluminal pressure above that of the pressure in the choledochal varices and thus prevent stasis in the flow of the bile. Moreover, the biliary abnormalities are patchy and mainly confined to the left duct, which may allow the bile to flow through other biliary channels.

In conclusion, biliary abnormalities simulating sclerosing cholangitis are very frequent in patients with extrahepatic portal venous obstruction. We believe these changes are caused by portal cavernoma/choledochal varices. These observations are important in the differential diagnosis of sclerosing cholangitis and also before considering these patients for biliary tract surgery.

We thank Mr M L Sharma for the photographic work.

1 Williams SM, Burnett DA, Mazer MU. Radiographic demonstration of common bile duct varices. Gastrointest Radiol 1982; 7: 69-70.

2 Dan SJ, Train JS, Cohen BA, Mitty MA. Common bile duct varices cholangiographic demonstration of a hazardous portosystemic communication. Am $\mathcal{f}$ Gastroenterol 1983; 78: 42-3.
3 Spira R, Widrich WC, Keush KD, Jackson BT, Katzman HE, Coello AA. Bile duct varices. Arch Surg 1985; 120: 1194-6.

$4 \mathrm{Kim}$ S, Chew FS. Choledochal varices. AfR 1988; 150: 578Kim $\mathrm{S}$.

5 Maxwell JW, Jackson FC. Splenoportovenography using a plastic hubbed catheter. Surg Gynecol Obstet 1962;124: 362.

6 Paquet KJ. Prophylactic endoscopic sclerosing treatment of Paquet KJ. Prophylactic endoscopic sclerosing treatment of
esophageal wall in varices. A prospective controlled esophageal wall in varices. A prospectiv

7 Dilawari JB, Chawla YK. Extrahepatic portal venous obstruction. Gut 1988; 29: 554-5.

8 Lebrec D, Benhamau JB. Ectopic varices in portal hypertension. Clin Gastroenterol 1985; 14: 105-21.

9 Chawla Y, Dilawari JB. Anorectal varices their frequency in cirrhotic and non-cirrhotic portal hypertension. Gut 1991; 32: 309-11.

10 Saint JA. The epicholedochal venous plexus and its importance as a means of identifying the common bile duct during operations on extrahepatic biliary tract. Br $\mathcal{F}$ Surg 1961; 48: operation.

11 Petren T. Die extrahepatischen gallenweqsveness and in repathologisch anatomischa Bedeutung. Verb Anat Ges 1932; 41: 138-43.

12 Ayoola EA, Vennes JA, Silvis JE, et al. Endoscopic retrograde intrahepatic cholangiography in liver disease. Gastrointes Endosc 1976; 22: 156-7.

13 Seltzer RA, Rossiter SB, Cooperman LR, et al. Hemobilia after needle biopsy of liver. $A \mathcal{F} R$ 1976; 127: 1035-6.

14 Cahow CE, Burrel M, Greco R. Hemobilia following percutaneous transhepatic cholangiography. Ann Surg 1977; 185: $235-41$.

15 Fraser J, Broun AK. A clinical syndrome associated with a rare anomaly of vena portel system. Surg Gynecol Obstet 1944; 78: $520-4$.

16 Choudhri G, Tandon RK, Nundy S, Misra NK. Common bile duct obstruction by portal cavernoma. Dig Dis Sci 1988; 33: $1626-8$. 